\title{
Product Quality Control Strategy of Dual Distribution Channel Structure in Three-Echelon Supply Chain
}

\section{Lilong Zhu ( $\nabla$ zhulilong2008@126.com )}

Shandong Normal University https://orcid.org/0000-0002-9697-3012

Bingjie Lu

Shandong Normal University

\section{Research Article}

Keywords: dual channel structure, three-echelon supply chain, Stackelberg dynamic game, product quality control strategy, simulation analysis

Posted Date: April 26th, 2021

DOI: https://doi.org/10.21203/rs.3.rs-295912/v1

License: (1) This work is licensed under a Creative Commons Attribution 4.0 International License.

Read Full License

Version of Record: A version of this preprint was published at Soft Computing on October 27th, 2021. See the published version at https://doi.org/10.1007/s00500-021-06406-9. 


\section{Title Page}

\section{Product Quality Control Strategy of Dual Distribution Channel}

\section{Structure in Three-echelon Supply Chain}

Lilong $\mathrm{Zhu}^{1,2^{*}}$, Bingjie $\mathrm{Lu}^{1,2}$

${ }^{1}$ School of Business, Shandong Normal University, Ji'nan, 250014, China

${ }^{1}$ Quality Research Center, Shandong Normal University, Ji’nan, 250014, China

* Corresponding author.

E-mail: zhulilong2008@126.com. Tel: +86-531-13853193366

Lilong Zhu, Ph.D. and Professor

Postdoctoral research in Shandong University, Ph.D. degree was granted in management science and engineering in Tongji University, Research scholar in College of Business, University of Illinois at Urbana-Champaign, USA, Visiting scholar in Tsinghua University, China. His research interests are product quality management in supply chain.

\section{Acknowledgments}

The authors are grateful to the referees for their valuable comments and their helps on how to improve the quality of our paper. This work was supported by the National Social Science Fund of China under grant No.20BGL272.

\section{Statistical data}

All the data is available and within the manuscript, no supplement materials data.

\section{Competing interests}

The authors declare that no competing interests exist.

\section{Short title}

Product Quality Control Strategy of Dual Distribution Channel in Supply Chain

\section{Total word count}

6457 words, 25 pages, 3 tables, 4 figures. 


\title{
Product Quality Control Strategy of Dual Distribution Channel
}

Structure in Three-echelon Supply Chain

\begin{abstract}
\end{abstract}
Based on the three-stage Stackelberg dynamic game model, this paper considers how to make product quality control strategy in the three-echelon supply chain consisting of the manufacturer, retailer and customer in the case of retailer dual channel structure (traditional retail channel, internet channel) and manufacturer dual channel structure (traditional retail channel, a third-party platform internet channel). When there are two types of decision model (decentralized decision, centralized decision), we analyze the demand price elasticity, market share ratio, revenue sharing ratio and quality cost coefficient how to influence the product demand, product quality level, retail price and direct price in different channels, expected revenue functions of manufacturer and retailer, consumer surplus and product quality control strategy. We find that: First of all, the retail price and direct price are positively related to product quality level, and the product quality level is negatively related with the demand price elasticity in traditional retail channel and the demand price elasticity in internet channel. What's more, the retailers' retail price in traditional retail channel will be higher than direct price in internet channel. Thirdly, in the case of centralized decision, the manufacturers' product quality level, retail price, joint expected revenue and consumer surplus will all rise, but the direct price will fall. Fourthly, when the manufacturer establishes the dual channel structure, i.e., entrusting the third-party platform to build the internet channel, the manufacturer's product quality level, retail price, direct price, expected revenue, and consumer surplus will all decline. Finally, we conduct the numerical example by Matlab 2018, which verifies the validity and credibility of our conclusions, and points out the direction for the specific application of the model in practice.

Key words: dual channel structure; three-echelon supply chain; Stackelberg dynamic game; product quality control strategy; simulation analysis 


\section{Introduction}

In recent years, with the rise of internet economy and e-commerce, more and more customers or consumers choose to buy products in internet channel. In 2018, e-commerce transactions in 28 major countries and regions reached 24.72 trillion USD, with online retail transactions totaling 2.97 trillion USD (Global E-commerce Data Report 2019). In the fourth quarter of 2019, U.S. e-commerce retail sales grew 16.4 percent to 187 billion USD, and reached 602 billion USD for the full year (U.S. Department of Commerce on February 19, 2020). In 2019, the amount of Chinese online retail sales has exceeded 1.62 trillion USD, up 16.5 percent from 2018 (the Chinese Ministry of Commerce on June 30, 2020). On November 11, 2020, Tmall's “Double Eleven” sales reached 76.2 billion USD, a year-on-year increase of 26\%; JD Mall's "Double Eleven" sales also reached 41.53 billion USD, a year-on-year increase of $32.8 \%$ (Chinanews.com on November 12, 2020). So, we can see that in addition to traditional retail channel, internet channel has gradually become an important way for product sales in the supply chain.

With the changing of customers or consumers' buying behavior, more and more enterprises begin to redesign or construct their distribution channel structures. For example, HP, Nike, Lenovo, Suning and Gome have opened internet channel in addition to traditional retail channel. Dell and Xiaomi, which used to focus on internet channel, are now beginning to sell products in traditional retail channel. While Apple and Haier have sold products in both traditional retail channel and internet channel from the beginning.

However, there are still some unresolved problems in the exploration of theory and practice. Firstly, how to construct different distribution channels and their influence on product quality decision in the three-echelon supply chain; What's more, influence on making product quality control strategy when the retailer establishes the dual channel structure or the manufacturer establishes the dual channel structure; Thirdly, when the manufacturer entrusts the third-party platform to build the internet channel or the retailer establishes the dual channel structure, how to influence the product quality, retail price and direct price; Finally, the influence of price demand elasticity in different distribution channels on product quality decision, price decision, expected revenue functions, and 
consumer surplus of the customer.

In this paper, we construct the three-stage Stackelberg dynamic game model and consider how to make product quality control strategy in the three-echelon supply chain when the retailer establishes the dual channel structure or the manufacturer establishes the dual channel structure. When there are decentralized decision and centralized decision, we analyze the demand price elasticity, market share ratio, revenue sharing ratio and quality cost coefficient how to influence the product demand, product quality level, retail price and direct price in different channels, expected revenue functions of manufacturer and retailer, consumer surplus and product quality control strategy.

The rest of our paper is organized as follows. In section 2, we review relevant literatures and we describe our model and make hypotheses in section 3. In section 4, we analyze the case that the retailer establishes the dual channel structure under decentralized decision and centralized decision. In section 5, we analyze the case that the manufacturer establishes the dual channel structure. We use Matlab 2018 to conduct numerical analysis in section 6. Finally, section 7 gives conclusions and future research direction.

\section{Literature Review}

At present, scholars around the world have conducted a great deal of researches on how to establish different distribution channel structures in the three-echelon supply chain, and how to formulate product quality control strategy under different distribution channel structures and two decision models (decentralized decision and centralized decision), mainly in the following three aspects.

The first aspect is mainly about the influence of distribution channels in the supply chain on product quality, selling price, corporate profits and consumer surplus. Chen J.X., et al. (2017) employ two themes in terms of channel-adding Pareto zone to characterize the impacts of channel structures on supply-chain performance, including the whole system's profit, each player's profit, and consumer surplus. Modak N.M., et al. (2019) examine a dual-channel supply chain under price and delivery-time dependent stochastic customer demand and find that uncertainty frequently arises in both retail and online channels which has an effect on the optimal order quantity and price. Tian L. and Jiang B.J. (2018) study 
how consumer-to-consumer product sharing in the supply chain affects the strategic choice of distribution channels, as well as the impact on manufacturers' profits and consumer surplus. Matsui K. (2017) apply an observable delay game framework developed in noncooperative game theory, investigate the timing problem concerning when a manufacturer managing dual-channel supply chains, consisting of a retail channel and a direct channel, should post its wholesale price and direct price. Wong H., et al. (2019) find that manufacturers adopt generic strategic choices in decentralized channel can reduce channel efficiency losses, and analyze its impact on channel profits and consumer surplus. Zhang J.Q., et al. (2019) consider the case that manufacturers establish a direct platform channel to reach customers directly and study the interrelationship between a platform's contract choice and a manufacturer's product quality decision.

The second aspect is about the strategic choices and decisions of different distribution channels, as well as the impact on channel coordination. Many scholars studied the distribution channel structure (Wang L.S., et al., 2017), mainly including direct channel structure (Wang C.X., et al., 2018), indirect channel structure (Luo Z., et al., 2018 and Dey L., et al., 2019) and mixed channel structure (Yan N.N., et al., 2020). Guo S.S. and Heese H.S. (2017) investigate how the manufacturer's optimal product variety decision differs when selling directly to customers (centralized decision) as compared to selling through a retailer (decentralized decision). Yang Z.B., et al. (2018) study the optimal distribution strategy of a supplier with limited capacity and find the supplier may adopt the supplier-only role, be the solo seller in the market, or use the dual-channel strategy and compete with its downstream buyer. Chen X., et al. (2017) examine how a direct channel added by a manufacturer can influence the decisions of the retailer and the manufacturer and further propose a retailer's margin contract that can coordinate the dual-channel supply chain and ensure that both the retailer and the manufacturer will be more profitable. Feng L.P., et al. (2017) investigate two problems that are comprised of designing and coordinating a reverse supply chain with a traditional and an online recycling channel and in the coordination problem, a contract with transfer and online recycling prices can coordinate the dual-recycling channel reverse supply chain but harms the dealer. Lan Y.Q., et al. (2018) show that the dual-channel system benefits the manufacturer and the retailer if 
the level of demand uncertainty exceeds a threshold and that the competition between the two distributors leads to the coordination of the downstream supply chain (the two distributors and the retailer). Rahmani K., et al. (2019) investigate the demand disruption management in a dual-channel supply chain producing and selling green products for the first time and results reveal that when the disruption increases the market scale, or when the greening cost decreases, the optimal prices will be increased in both decision-making structures. Song B.Q. et al. (2020) study dynamic channel control and pricing of a single perishable product distributed through multiple channels and the results show that, the magnitude of the opportunity cost of capacity uniquely determines the optimal channel control.

The third aspect is about how to prevent product quality risks in the strategies of supply chain distribution channels. Liu Y., et al. (2018) study that the uncertainty of market size will reduce the difference of product quality and determine the optimal product quality level in the centralized and decentralized distribution channel structure. Sarkar B., et al. (2016) discuss how to make product quality decision in different distribution channel strategies and how to prevent channel quality risks by building product quality decision model. Zhang J.Q., et al. (2019) analyze the relationship between platform contract selection and manufacturer's product quality decision when online sales channels exist in the supply chain, and further discuss the influence of platform sales and contract design on reducing product quality risks by building a revenue sharing model. Huang H.F., et al. (2019) develop game-theoretic models for a supply chain with a manufacturer and a PI (parallel importer), in which the manufacturer needs to determine distribution structure, product quality, and retail price and find that the advertising effect may motivate the manufacturer to improve product quality. Zhang J.X., et al. (2019) show that manufacturer encroachment leads to a lower quality when the manufacturer's direct selling cost is intermediate and compared to the full and no information cases, asymmetric information may increase quality when direct selling is relatively efficient while decrease quality otherwise. Jabarzare N. and Rasti-Barzoki M. (2020) investigate how the packaging company can influence the quality of products through packaging products in a dual-channel supply chain and find that from quality-seeking customers' perspective, the 
cooperation of manufacturer and packaging company under profit-sharing contract is more preferable. Zhu L.L. $(2011,2020)$ analyzes three types of distribution channels strategy (direct channel, retail channel and mixed channel) in the context of how they influence a manufacturer's product quality decision and quality prevention strategy and focuses on how to control product quality and design quality contract in supply chain when moral hazard exists, which proposing suggestions for quality control strategy and contract design in the supply chain under the conditions of asymmetric information.

Therefore, compared with previous scholars, this paper is mainly different in the following three aspects. Firstly, based on the three-stage Stackelberg dynamic game, this paper constructs the product quality control strategy model in the three-echelon supply chain consisting of the manufacturer, retailer and customer and analyzes the influence of retailer dual channel structure (traditional retail channel, internet channel) and manufacturer dual channel structure (traditional retail channel, a third party-platform internet channel) on product quality decision. Then, when there are decentralized decision and centralized decision, we discuss the demand price elasticity, market share ratio, revenue sharing ratio and quality cost coefficient how to influence the product demand, product quality level, retail price and direct price in different channels, expected revenue functions of manufacturer and retailer, consumer surplus and product quality control strategy. Finally, we use Matlab 2018 for simulation analysis, pointing out the direction for the practical application of this model.

\section{Model Description and Hypotheses}

In this paper, we construct the three-echelon supply chain consisting of the manufacturer, retailer, third-party platform and customer and make the following hypotheses.

H1. The manufacturer, retailer, third-party platform and customer are risk neutral.

$\mathrm{H} 2$. There are two dual channel structures which are the retailer dual channel structure (traditional retail channel, internet channel) and the manufacturer dual channel structure (traditional retail channel, a third party-platform internet channel).

H3. The manufacturer has two decision models to choose which are decentralized 
decision and centralized decision.

H4. The manufacturer determines the quality level and wholesale price. The retailer determines the retail price and when it establishes the internet channel, it determines direct price. The customer determines product demand.

H5. In the dual channel structure, the demand price elasticity coefficient is different between traditional retail channel and internet channel.

H6. In the distribution channel strategy of supply chain, both the manufacturer and the retailer pursue the maximization of expected revenue, and the customer pursues the maximization of consumer surplus.

The relevant variables and parameters are described as follows.

$$
q \text { : Manufacturer's product quality level, } q \in[0,+\infty) \text {. }
$$

$w$ : Manufacturer's product wholesale price.

$C(q)$ : Manufacturer's product production cost. $C(q)=k q^{2} / 2$, so $C^{\prime}(q)>0$ $C^{\prime \prime}(q)>0$, and $k$ is product quality cost coefficient.

$p_{r}:$ Product retail price in traditional retail channel.

$p_{e}:$ Product direct price in internet channel.

The customer's demand function in traditional retail channel is $Q_{r}=\alpha M-\eta_{r} p_{r} / q$.

The customer's demand function in internet channel is $Q_{e}=(1-\alpha) M-\eta_{e} p_{e} / q$.

$M$ is the maximum demand of the customer, $\alpha$ is market share ratio in traditional retail channel, $\eta_{r}$ is product price elasticity coefficient in traditional retail channel, $\eta_{e}$ is product price elasticity coefficient in internet channel, and the customer is more price sensitive in internet channel, so $\eta_{e}>\eta_{r}$.

$\lambda$ : Revenue sharing ratio between manufacturer and the third-party platform.

The customer's consumer surplus is $v q-p_{i} \cdot v \sim U(0, M)$ and $f(v)$ is probability density. So, the relationship of dual channel structure constructed in this paper is shown in Figure 1. 
(Figure 1 The relationship of dual channel structure)

Case 1 When the retailer establishes the dual channel structure, the sequence of three-stage Stackelberg dynamic game is as follows.

Stage 1, the manufacturer determines the product quality level. Stage 2, the manufacturer determines the wholesale price. Stage 3, the retailer determines the retail price in traditional retail channel and the direct price in internet channel respectively.

Case 2 When the manufacturer establishes the dual channel structure, the sequence of three-stage Stackelberg dynamic game is as follows.

Stage 1, the manufacturer determines the product quality level. Stage 2, the manufacturer determines the wholesale price in traditional retail channel and revenue sharing ratio in internet channel respectively. Stage 3, the retailer determines the retail price and the third-party platform determines the direct price.

\section{The Retailer Dual Channel Structure}

\subsection{Decentralized Decision}

When the retailer establishes the dual channel structure (traditional retail channel, internet channel), in the case of decentralized decision (manufacturer and retailer make independent decision respectively), first of all, the manufacturer determines the product quality level, then the wholesale price. The retailer determines the retail price in traditional retail channel and the direct price in internet channel respectively. Therefore, we construct the Stackelberg game model of manufacturer and retailer, which is as follows.

$$
\begin{aligned}
& \operatorname{MaxE}_{M}(q, w)=\left(w-k q^{2} / 2\right)\left[M-\left(\eta_{r} p_{r}+\eta_{e} p_{e}\right) / q\right] \\
& \text { s.t. }\left\{p_{r}, p_{e}\right\}=\arg \operatorname{MaxE}_{\mathrm{R}}\left(p_{r}, p_{e}\right) \\
& \operatorname{MaxE}_{\mathrm{R}}\left(p_{r}, p_{e}\right)=\left(p_{r}-w\right)\left(\alpha M-\eta_{r} p_{r} / q\right)+\left(p_{e}-w\right)\left[(1-\alpha) M-\eta_{e} p_{e} / q\right]
\end{aligned}
$$

Equation (1) is the manufacturer's expected revenue function. Equation (3) is the retailer's expected revenue function.

Proposition 1 When the retailer establishes the dual channel structure, in the case of decentralized decision, the retail price in traditional retail channel and the direct price in internet channel are positively related to product quality level (i.e., increasing function). 
The product quality level is negatively related to demand price elasticity in traditional retail channel and demand price elasticity in internet channel (i.e., decreasing function). So, the optimal product quality level is $q^{D^{*}}=2 M /\left[3 k\left(\eta_{r}+\eta_{e}\right)\right]$.

Proof Use backwards induction method to solve, and take the first and second partial derivatives of equation (3) with respect to $p_{r}$ and $p_{e}$ respectively, and get

$$
\begin{aligned}
& \partial E \Pi_{R} / \partial p_{r}=\alpha M+\eta_{r} w / q-2 \eta_{r} p_{r} / q=0, \partial^{2} E \Pi_{R} / \partial p_{r}^{2}=-2 \eta_{r} / q<0 \\
& \partial E \Pi_{R} / \partial p_{e}=(1-\alpha) M+\eta_{e} w / q-2 \eta_{e} p_{e} / q=0, \partial^{2} E \Pi_{R} / \partial p_{e}^{2}=-2 \eta_{e} / q<0
\end{aligned}
$$

From equations (4) and (5), we get

$$
\begin{aligned}
& p_{r}=\alpha M q /\left(2 \eta_{r}\right)+w / 2 \\
& p_{e}=(1-\alpha) M q /\left(2 \eta_{e}\right)+w / 2
\end{aligned}
$$

Take the first partial derivative of equations (6) and (7) with respect to $q$ respectively, and get

$$
\partial p_{r} / \partial q=\alpha M /\left(2 \eta_{r}\right)>0 \text { (increasing function) }
$$

$$
\partial p_{e} / \partial q=(1-\alpha) M /\left(2 \eta_{e}\right)>0 \text { (increasing function) }
$$

Substitute equations (6) and (7) into equation (1), and get

$$
E \Pi_{M}(q, w)=\left(w-k q^{2} / 2\right)\left[M / 2-\left(\eta_{r}+\eta_{e}\right) w / 2 q\right]
$$

Take the first partial derivative of equation (10) with respect to $w$, and get

$$
w=M q / 2\left(\eta_{r}+\eta_{e}\right)+k q^{2} / 4
$$

Substitute equation (11) into equation (10), and get

$$
E \Pi_{M}(q)=\left[M q / 2\left(\eta_{r}+\eta_{e}\right)-k q^{2} / 4\right]\left[M / 4-\left(\eta_{r}+\eta_{e}\right) k q / 8\right]
$$

Take the first and second partial derivative of equation (12) with respect to $q$, and get

$$
q_{1}=2 M /\left[k\left(\eta_{r}+\eta_{e}\right)\right] \text { or } q_{2}=2 M /\left[3 k\left(\eta_{r}+\eta_{e}\right)\right]
$$

$\partial^{2} E \Pi_{M}(q) / \partial q^{2}=3 k^{2}\left(\eta_{r}+\eta_{e}\right) q / 16-M k / 4<0 \quad$ (concave function)

$$
q<4 M /\left[3 k\left(\eta_{r}+\eta_{e}\right)\right]
$$


From equation (15), we get

$$
\partial q^{D^{*}} / \partial \eta_{r}=-2 M / 27 k^{2}\left(\eta_{r}+\eta_{e}\right)^{2}<0 \quad \text { (decreasing function) }
$$

$$
\partial q^{D^{*}} / \partial \eta_{e}=-2 M / 27 k^{2}\left(\eta_{e}+\eta_{r}\right)^{2}<0 \quad \text { (decreasing function) }
$$

\section{QED.}

Proposition 1 indicates that when the retailer establishes the dual channel structure, in the case of decentralized decision, the retail price in traditional retail channel and the direct price in internet channel increase with the product quality level improving (i.e., increasing function, positive correlation); the product quality level will decrease with demand price elasticity in traditional retail channel and demand price elasticity in internet channel increasing (i.e., decreasing function, negative correlation).

Proposition 2 The retailer's expected revenue function is a joint concave function about the retail price and direct price and the stationary point $\left\{p_{r}^{D^{*}}, p_{e}^{D^{*}}\right\}$ will make $E \Pi_{R}^{D^{*}}$ take the maximum. $p_{r}^{D^{*}}>p_{e}^{D^{*}}$,which indicates that the retail price in traditional retail channel will be higher than the direct price in internet channel.

Proof Solve the Hessian matrix of equation (3) about $p_{r}$ and $p_{e}$, and get

$$
H=\left[\begin{array}{cc}
\partial^{2} E \Pi_{R} / \partial p_{r}^{2} & \partial^{2} E \Pi_{R} / \partial p_{r} \partial p_{e} \\
\partial^{2} E \Pi_{R} / \partial p_{e} \partial p_{r} & \partial^{2} E \Pi_{R} / \partial p_{e}^{2}
\end{array}\right]=\left[\begin{array}{cc}
-2 \eta_{r} / q & 0 \\
0 & -2 \eta_{e} / q
\end{array}\right]
$$

The first-order principal minor of the matrix $H$ is less than zero and the second-order principal minor is greater than zero, which shows that $H$ is a negative definite matrix.

$E \Pi_{R}$ is a joint concave function and it has local maximum.

Substitute equation (15) into equation (11), and get

$$
w^{D^{*}}=4 M^{2} / 9 k\left(\eta_{r}+\eta_{e}\right)^{2}
$$

Substitute equations (15) and (16) into equations (6) and (7), and get

$$
p_{r}^{D^{*}}=\alpha M^{2} / 3 k \eta_{r}\left(\eta_{r}+\eta_{e}\right)+2 M^{2} / 9 k\left(\eta_{r}+\eta_{e}\right)^{2}
$$




$$
p_{e}^{D^{*}}=(1-\alpha) M^{2} / 3 k \eta_{e}\left(\eta_{r}+\eta_{e}\right)+2 M^{2} / 9 k\left(\eta_{r}+\eta_{e}\right)^{2}
$$

QED.

Proposition 2 indicates that the retailer's expected revenue function is a joint concave function about the retail price and direct price. So, there are optimal retail price and optimal direct price to make the retailer's expected revenue maximum and the retail price in traditional retail channel will be higher than the direct price in internet channel, which is consistent with the actual situation.

Corollary 2.1 The expected revenue functions of manufacturer and retailer are negatively related to the demand price elasticity in traditional retail channel and the demand price elasticity in internet channel respectively (i.e., decreasing function).

Proof Substitute equations (15), (16), (17) and (18) into equations (1) and (3), and get

$$
\begin{aligned}
& E \Pi_{M}^{D^{*}}=M^{3} / 27 k\left(\eta_{r}+\eta_{e}\right)^{2} \\
& E \Pi_{R}^{D^{*}}=\left[\eta_{e} \alpha^{2}+\eta_{r}(1-\alpha)^{2}\right] M^{3} /\left[6 k \eta_{r} \eta_{e}\left(\eta_{r}+\eta_{e}\right)\right]-4 M^{3} / 27 k\left(\eta_{r}+\eta_{e}\right)^{2}
\end{aligned}
$$

Take the first partial derivative of equations (19) and (20) with respect to $\eta_{r}$ and $\eta_{e}$ respectively, and get

$$
\partial E \Pi_{M}^{D^{*}} / \partial \eta_{r}<0 、 \partial E \Pi_{M}^{D^{*}} / \partial \eta_{e}<0 \text { (negative correlation, decreasing function) }
$$
$\partial E \Pi_{R}^{D^{*}} / \partial \eta_{r}<0 、 \partial E \Pi_{R}^{D^{*}} / \partial \eta_{e}<0$ (negative correlation, decreasing function)

$$
\text { QED. }
$$

Corollary 2.1 indicates that the expected revenue functions of manufacturer and retailer will decrease with the demand price elasticity in traditional retail channel and the demand price elasticity in internet channel increasing.

So, the customer's consumer surplus is

$$
\begin{aligned}
C S^{D^{*}} & =\int_{0}^{\alpha M}\left(v q^{D^{*}}-p_{r}^{D^{*}}\right) f(v) d v+\int_{\alpha M}^{M}\left(v q^{D^{*}}-p_{e}^{D^{*}}\right) f(v) d v \\
& =\left[\eta_{r} \eta_{e}-\eta_{e} \alpha^{2}-\eta_{r}(1-\alpha)^{2}\right] M^{2} /\left[3 k \eta_{r} \eta_{e}\left(\eta_{r}+\eta_{e}\right)\right]-2 M^{2} / 9 k\left(\eta_{r}+\eta_{e}\right)^{2}
\end{aligned}
$$


$C S^{D^{*}}$ is the customer's consumer surplus when retailer establishes the dual channel structure in the case of decentralized decision.

\subsection{Centralized Decision}

The manufacturer and the retailer make centralized decision, which is the manufacturer and the retailer make joint decision, and the supply chain system composed of the manufacturer and the retailer is vertically integrated. So, we construct the supply chain system decision model composed of the manufacturer and the retailer, the model is as follows.

$$
\operatorname{MaxE} \Pi_{M R}\left(q, p_{r}, p_{e}\right)=\left(p_{r}-k q^{2} / 2\right)\left(\alpha M-\eta_{r} p_{r} / q\right)+\left(p_{e}-k q^{2} / 2\right)\left[(1-\alpha) M-\eta_{e} p_{e} / q\right]
$$

Equation (22) is supply chain joint expected revenue function.

Proposition 3 In the case of centralized decision, the manufacturer and the retailer make joint decision. The manufacturer's product quality level will be higher than that in the case of decentralized decision, i.e. $q^{C^{*}}>q^{D^{*}}$.

Proof Use backwards induction method to solve, and take the first partial derivative of equation (22) with respect to $p_{r}$ and $p_{e}$ respectively, and get

$$
p_{r}=\alpha M q /\left(2 \eta_{r}\right)+k q^{2} / 4
$$

$$
p_{e}=(1-\alpha) M q /\left(2 \eta_{e}\right)+k q^{2} / 4
$$

Solve the Hessian matrix of equation (22) about $p_{r}, p_{e}$ and $q$, and get

$H=\left[\begin{array}{ccc}\partial^{2} E \Pi_{M R} / \partial p_{r}^{2} & \partial^{2} E \Pi_{M R} / \partial p_{r} \partial p_{e} & \partial^{2} E \Pi_{M R} / \partial p_{r} \partial q \\ \partial^{2} E \Pi_{M R} / \partial p_{e} \partial p_{r} & \partial^{2} E \Pi_{M R} / \partial p_{e}^{2} & \partial^{2} E \Pi_{M R} / \partial p_{e} \partial q \\ \partial^{2} E \Pi_{M R} / \partial q \partial p_{r} & \partial^{2} E \Pi_{M R} / \partial q \partial p_{e} & \partial^{2} E \Pi_{M R} / \partial q^{2}\end{array}\right]=\left[\begin{array}{ccc}-2 \eta_{r} / q & 0 & k \eta_{r} / 2+2 \eta_{r} p_{r} / q^{2} \\ 0 & -2 \eta_{e} / q & k \eta_{e} / 2+2 \eta_{e} p_{e} / q^{2} \\ k \eta_{r} / 2+2 \eta_{r} p_{r} / q^{2} & k \eta_{e} / 2+2 \eta_{e} p_{e} / q^{2} & -k M-2\left(\eta_{r} p_{r}^{2}+\eta_{e} p_{e}^{2}\right) / q^{3}\end{array}\right]$

The first-order principal minor of the matrix $H$ is less than zero, the second-order principal minor is greater than zero and the third-order principal minor is less than zero, which shows that $H$ is a negative definite matrix.

$E \Pi_{M R}$ is a joint concave function.

Substitute equations (23) and (24) into equation (22), and get

$$
E \Pi_{M R}(q)=\left(\alpha M q / 2 \eta_{r}-k q^{2} / 4\right)\left(\alpha M / 2-\eta_{r} k q / 4\right)+\left((1-\alpha) M q / 2 \eta_{e}-k q^{2} / 4\right)\left[(1-\alpha) M / 2-\eta_{e} k q / 4\right]
$$




$$
q_{1}=2 M(2-\sqrt{\varepsilon}) /\left[3 k\left(\eta_{r}+\eta_{e}\right)\right] \text { or } q_{2}=2 M(2+\sqrt{\varepsilon}) /\left[3 k\left(\eta_{r}+\eta_{e}\right)\right]
$$

$$
q<4 M /\left[3 k\left(\eta_{r}+\eta_{e}\right)\right]
$$

From equations (26) and (28), we get

$$
q^{C^{*}}=2 M(2-\sqrt{\varepsilon}) /\left[3 k\left(\eta_{r}+\eta_{e}\right)\right]
$$

$$
\varepsilon=\left[4 \eta_{r} \eta_{e}-3\left(\eta_{r}+\eta_{e}\right)\left(\eta_{e} \alpha^{2}+\eta_{r}(1-\alpha)^{2}\right] / \eta_{r} \eta_{e}\right.
$$

$0<\alpha<1, \quad 0<(1-\alpha)<1, \quad \eta_{r}<\eta_{e}$

$\varepsilon<1$

Compare equation (29) with (15), and get

$q^{C^{*}}=2 M(2-\sqrt{\varepsilon}) /\left[3 k\left(\eta_{r}+\eta_{e}\right)\right]>2 M /\left[3 k\left(\eta_{r}+\eta_{e}\right)\right]=q^{D^{*}}$

QED.

Proposition 3 indicates that when the retailer establishes the dual channel structure, in

the case of centralized decision, the manufacturer's product quality level will be higher than that in the case of decentralized decision.

From proposition 3, we can get the following corollaries.

Corollary 3.1 The price in traditional retail channel will rise, i.e. $p_{r}^{C^{*}}>p_{r}^{D^{*}}$. The price in internet channel will fall, i.e. $p_{e}^{C^{*}}<p_{e}^{D^{*}}$.

Proof Substitute equation (29) into equations (23) and (24) respectively, and get

$$
p_{r}^{C^{*}}=\alpha M^{2}(2-\sqrt{\varepsilon}) /\left[3 k \eta_{r}\left(\eta_{r}+\eta_{e}\right)\right]+M^{2}(2-\sqrt{\varepsilon})^{2} /\left[9 k\left(\eta_{r}+\eta_{e}\right)^{2}\right]
$$

$$
p_{e}^{C^{*}}=(1-\alpha) M^{2}(2-\sqrt{\varepsilon}) /\left[3 k \eta_{e}\left(\eta_{r}+\eta_{e}\right)\right]+M^{2}(2-\sqrt{\varepsilon})^{2} /\left[9 k\left(\eta_{r}+\eta_{e}\right)^{2}\right]
$$


Corollary 3.1 indicates that when the retailer establishes the dual channel structure, compared with decentralized decision, centralized decision make the price in traditional retail channel increase, but make the price in internet channel decrease.

Corollary 3.2 In the case of centralized decision, the supply chain system joint expected revenue will higher than the sum of the expected revenues of the manufacturer and the retailer in the case of decentralized decision, i.e., $E \Pi_{M R}^{C^{*}}>E \Pi_{M}^{D^{*}}+E \Pi_{R}^{D^{*}}$.

From equations (19) and (20), we get

$$
\begin{aligned}
& E \Pi_{M}^{D^{*}}+E \Pi_{R}^{D^{*}}=M^{3}\left[\eta_{e} \alpha^{2}+\eta_{r}(1-\alpha)^{2}\right] /\left[6 k \eta_{r} \eta_{e}\left(\eta_{r}+\eta_{e}\right)\right]-6 M^{3} /\left[54 k\left(\eta_{r}+\eta_{e}\right)^{2}\right] \\
& E \Pi_{M R}^{C^{*}}-\left(E \Pi_{M}^{D^{*}}+E \Pi_{R}^{D^{*}}\right)= \\
& M^{3}(1-\sqrt{\varepsilon})\left[\eta_{e} \alpha^{2}+\eta_{r}(1-\alpha)^{2}\right] /\left[6 k \eta_{r} \eta_{e}\left(\eta_{r}+\eta_{e}\right)\right]+M^{3}\left[6-(2-\sqrt{\varepsilon})^{2}(4+\sqrt{\varepsilon})\right] /\left[54 k\left(\eta_{r}+\eta_{e}\right)^{2}\right]>0 \\
& E \Pi_{M R}^{C^{*}}>\left(E \Pi_{M}^{D^{*}}+E \Pi_{R}^{D^{*}}\right)
\end{aligned}
$$

QED.

Corollary 3.2 indicates that in the case of centralized decision, the supply chain system joint expected revenue will increase, because the centralized decision enables the manufacturer and retailer to make joint decision, forms the vertical integration of the supply chain system and improves the operation efficiency.

Corollary 3.3 In the case of centralized decision, the consumer surplus of the customer will be higher than that in the case of decentralized decision, i.e., $C S^{C^{*}}>C S^{D^{*}}$.

Proof From equations (29), (31) and (32), we get

$$
C S^{C^{*}}=M^{2}(2-\sqrt{\varepsilon})\left[\eta_{r} \eta_{e}-\eta_{e} \alpha^{2}-\eta_{r}(1-\alpha)^{2}\right] /\left[3 k \eta_{r} \eta_{e}\left(\eta_{r}+\eta_{e}\right)\right]-M^{2}(2-\sqrt{\varepsilon}) /\left[9 k\left(\eta_{r}+\eta_{e}\right)^{2}\right]
$$

Compare equation (34) with (21), and get

$$
C S^{C^{*}}-C S^{D^{*}}=M^{2}(1-\sqrt{\varepsilon})\left[\eta_{r} \eta_{e}-\eta_{e} \alpha^{2}-\eta_{r}(1-\alpha)^{2}\right] /\left[3 k \eta_{r} \eta_{e}\left(\eta_{r}+\eta_{e}\right)\right]+M^{2} \sqrt{\varepsilon} /\left[9 k\left(\eta_{r}+\eta_{e}\right)^{2}\right]>0
$$

$C S^{C^{*}}>C S^{D^{*}}$

QED. 
Corollary 3.3 indicates that in the case of centralized decision, the consumer surplus of the customer will be higher than that in the case of decentralized decision, which shows that centralized decision is also beneficial to the customer.

\section{The Manufacturer Dual Channel Structure}

When the manufacturer establishes the dual channel structure, the manufacturer builds its own traditional retail channel and entrusts the third-party platform to build the internet channel. The manufacturer and the third-party platform determine the revenue sharing ratio $\lambda$ (revenue sharing contract). The manufacturer determines the product quality level and wholesale price. The retailer determines the retail price and the third-party platform determines internet direct price. Therefore, we construct the Stackelberg game model between the manufacturer, retailer and third-party platform, which is as follows.

$$
\operatorname{MaxE}_{M}(q, w)=\left(w-k q^{2} / 2\right)\left(\alpha M-\eta_{r} p_{r} / q\right)+\left(\lambda p_{e}-k q^{2} / 2\right)\left[(1-\alpha) M-\eta_{e} p_{e} / q\right]
$$

s.t. $\quad p_{r}=\arg \operatorname{MaxE}_{R}$

$$
p_{e}=\arg \operatorname{MaxE}_{T}
$$

$$
\operatorname{MaxE}_{R}\left(p_{r}\right)=\left(p_{r}-w\right)\left(\alpha M-\eta_{r} p_{r} / q\right)
$$

$$
\operatorname{MaxE}_{T}\left(p_{e}\right)=(1-\lambda) p_{e}\left[(1-\alpha) M-\eta_{e} p_{e} / q\right]
$$

Equation (35) is the manufacturer's expected revenue function, equation (36) is the retailer's expected revenue function and equation (37) is the third-party platform's expected revenue function.

Proposition 4 When the manufacturer establishes the dual channel structure, i.e., entrusting the third-party to build the internet channel, the manufacturer's product quality level is positively related to the revenue sharing ratio (i.e., increasing function). And its product quality level is lower than that when the retailer establishes the dual channel structure under decentralized decision and centralized decision, i.e. $q^{T^{*}}<q^{D^{*}}<q^{C^{*}}$.

Proof Use backwards induction method to solve, and take the first partial derivative of equations (36) and (37) with respect to $p_{r}$ and $p_{e}$ respectively, and get

$$
p_{r}=\alpha M q /\left(2 \eta_{r}\right)+w / 2
$$




$$
p_{e}=(1-\alpha) M q /\left(2 \eta_{e}\right)
$$

Substitute equations (38) and (39) into equation (35), and get

$$
E \Pi_{M}(q, w)=\left(w-k q^{2} / 2\right)\left(\alpha M / 2-\eta_{r} w / 2 q\right)+(1-\alpha) M / 2\left(\lambda(1-\alpha) M q / 2 \eta_{e}-k q^{2} / 2\right)
$$

Take the first partial derivative of equation (40) with respect to $w$, and get

$$
w=\alpha M q / 2 \eta_{r}+k q^{2} / 4
$$

Substitute equation (41) into equation (40), and get

$$
E \Pi_{M}(q)=\left(\alpha M q / 2 \eta_{r}-k q^{2} / 4\right)\left(\alpha M / 4-k \eta_{r} q / 8\right)+(1-\alpha) M / 2\left(\lambda(1-\alpha) M q / 2 \eta_{e}-k q^{2} / 2\right)
$$

Take the first and second partial derivative of equation (42) with respect to $q$, and get

$$
q_{1}=[4(2-\alpha) M-2 M \sqrt{\eta}] / 3 k \eta_{r} \text { or } q_{2}=[4(2-\alpha) M+2 M \sqrt{\eta}] / 3 k \eta_{r}
$$

$\eta=4(2-\alpha)^{2}-3 \alpha^{2}-6 \eta_{r} \eta_{e}^{-1} \lambda(1-\alpha)^{2}$

From equations (43) and (44), we get

$$
q^{T^{*}}=[4(2-\alpha) M-2 M \sqrt{\eta}] / 3 k \eta_{r}
$$

From equation (45), we get

$$
q^{T^{*}}(\lambda=1) / q^{D^{*}}=\left(\eta_{r}+\eta_{e}\right)(4-2 \alpha-\sqrt{\eta}) / \eta_{r}<1
$$

$$
q^{T^{*}}(\lambda=1)<q^{D^{*}}
$$

So, when $\lambda \in[0,1], q^{T^{*}}<q^{D^{*}}$

$$
q^{T^{*}}<q^{D^{*}}<q^{C^{*}}
$$

QED.

Proposition 4 indicates that when the manufacturer establishes the dual channel 
structure entrusting the third-part platform to build the internet channel, the manufacturer's product quality level is positively related to the revenue sharing ratio. And its product quality level is lower than that when the retailer establishes the dual channel structure under decentralized decision and centralized decision.

Substitute equation (45) into equation (41), and get

$$
w^{T^{*}}=\left[\left(16+\eta-2 \alpha^{2}-4 \alpha\right)-(8-\alpha) \sqrt{\eta}\right] M^{2} / 9 k \eta_{r}^{2}
$$

Substitute equations (45) and (49) into equations (38) and (39) respectively, and get

$$
\begin{aligned}
& p_{r}^{T^{*}}=\left[\left(16+\eta-14 \alpha^{2}+20 \alpha\right)-(8+5 \alpha) \sqrt{\eta}\right] M^{2} / 18 k \eta_{r}^{2} \\
& p_{e}^{T^{*}}=[2(1-\alpha)(2-\alpha)-(1-\alpha) \sqrt{\eta}] M^{2} / 3 k \eta_{r} \eta_{e}
\end{aligned}
$$

Substitute equations (45), (49), (50) and (51) into equations (35), (36) and (37) respectively, and get

$$
\begin{aligned}
& E \Pi_{R}^{T^{*}}=\left[\left(-10 \alpha^{2}+28 \alpha-\eta-16\right)-(7 \alpha-8) \sqrt{\eta}\right]^{2} M^{3} / 18 k \eta_{r}^{2}[24(2-\alpha)-12 \sqrt{\eta}] \\
& E \Pi_{T}^{T^{*}}=[2(1-\alpha)(2-\alpha)-(1-\alpha) \sqrt{\eta}]^{2}(1-\lambda) M^{3} / 3 k \eta_{r} \eta_{e}[4(2-\alpha)-2 \sqrt{\eta}]
\end{aligned}
$$$$
E \Pi_{M}^{T^{*}}=\frac{\left[\left(6\left(\alpha^{2}-3 \alpha+2\right) \lambda \eta_{r}-2\left(4 \alpha^{2}-16 \alpha+\eta+16\right) \eta_{e}\right)-\left(3(1-\alpha) \lambda \eta_{r}-8(2-\alpha) \eta_{e}\right) \sqrt{\eta}\right]\left[2\left(\alpha^{2}-3 \alpha+2\right)-(1-\alpha) \sqrt{\eta}\right] M^{3}}{9 k \eta_{r}^{2} \eta_{e}[4(2-\alpha)-2 \sqrt{\eta}]}
$$

$$
+\frac{\left[\left(-10 \alpha^{2}+28 \alpha-\eta-16\right)-(7 \alpha-8) \sqrt{\eta}\right]^{2} M^{3}}{9 k \eta_{r}^{2}[24(2-\alpha)-12 \sqrt{\eta}]}
$$

So, the customer's consumer surplus is

$$
\begin{aligned}
C S^{T^{*}}= & \int_{0}^{\alpha M}\left(v q^{T^{*}}-p_{r}^{T^{*}}\right) f(v) d v+\int_{\alpha M}^{M}\left(v q^{T^{*}}-p_{e}^{T^{*}}\right) f(v) d v \\
= & {\left[12(2-\alpha) \eta_{r}-\alpha\left(16+\eta-14 \alpha^{2}+20 \alpha\right)-\left(6 \eta_{r}-8 \alpha-5 \alpha^{2}\right) \sqrt{\eta}\right] M^{2} / 18 k \eta_{r}^{2} } \\
& +\left[2(1-\alpha)^{2}(2-\alpha)-(1-\alpha)^{2} \sqrt{\eta}\right] M^{2} / 3 k \eta_{r} \eta_{e}
\end{aligned}
$$

$C S^{T^{*}}$ is the customer's consumer surplus when the manufacturer establishes the dual channel structure.

\section{Numerical Analysis}

The manufacturer $\mathrm{M}$ provides a certain type of electronic products to the market. In addition to selling electronic products through retailer $\mathrm{R}, \mathrm{M}$ can also entrust the third-party 
488 platform (such as Amazon, eBay, Tmall, JD, etc.) to sell electronic products. The 489 production cost coefficient of $\mathrm{M}$ is 2 USD per piece, and the basic demand of customers 490 (consumers) is 30 pieces per day. The demand price elasticity coefficient in internet 491 channel is greater than that in traditional retail channel (i.e. $\eta_{e}=2 \eta_{r}$ ). The revenue sharing

492

493

494

495

496

497

498

499

500

501

ratio of the manufacturer is 0.5 . We will analyze changes in product quality level, wholesale price, retail price, direct price, market demand, expected revenue and customer's consumer surplus in traditional retail channel and internet channel.

Equations(15)-(21) are the description of the retailer dual channel structure (decentralized decision), equations(29)-(34) are the description of the retailer dual channel structure (centralized decision), and equations(45) and (49)-(55) are the description of the manufacturer dual channel structure (entrusting the third-party platform to build internet channel), we conduct the numerical analysis by Matlab 2018, and the results are shown in Table 1-Table 3 and Figure 2-Figure 4.

Table1 The retailer dual channel structure (decentralized decision)

\begin{tabular}{cccccccccc}
\hline$\eta_{r}$ & $\eta_{e}$ & $q^{D^{*}}$ & $w^{D^{*}}$ & $p_{r}^{D^{*}}$ & $p_{e}^{D^{*}}$ & $E \Pi_{R}^{D^{*}}$ & $E \Pi_{M}^{D^{*}}$ & $E \Pi_{M R}^{D^{*}}$ & $C S^{D^{*}}$ \\
\hline 1.000 & 2.000 & 3.333 & 22.222 & 36.111 & 23.611 & 59.028 & 55.556 & 114.583 & 20.139 \\
1.100 & 2.200 & 3.030 & 18.365 & 29.844 & 19.513 & 48.783 & 45.914 & 94.697 & 20.776 \\
1.200 & 2.400 & 2.778 & 15.432 & 25.077 & 16.397 & 40.992 & 38.580 & 79.572 & 20.930 \\
1.300 & 2.600 & 2.564 & 13.149 & 21.368 & 13.971 & 34.928 & 32.873 & 67.801 & 20.792 \\
1.400 & 2.800 & 2.381 & 11.338 & 18.424 & 12.046 & 30.116 & 28.345 & 58.461 & 20.479 \\
1.500 & 3.000 & 2.222 & 9.877 & 16.049 & 10.494 & 26.235 & 24.691 & 50.926 & 20.062 \\
1.600 & 3.200 & 2.083 & 8.681 & 14.106 & 9.223 & 23.058 & 21.701 & 44.759 & 19.586 \\
1.700 & 3.400 & 1.961 & 7.689 & 12.495 & 8.170 & 20.425 & 19.223 & 39.648 & 19.079 \\
1.800 & 3.600 & 1.852 & 6.859 & 11.145 & 7.287 & 18.218 & 17.147 & 35.365 & 18.561 \\
1.900 & 3.800 & 1.754 & 6.156 & 10.003 & 6.540 & 16.351 & 15.389 & 31.741 & 18.044 \\
2.000 & 4.000 & 1.667 & 5.556 & 9.028 & 5.903 & 14.757 & 13.889 & 28.646 & 17.535 \\
\hline
\end{tabular}

From Table 1, we can see that when the retailer establishes the dual channel structure (decentralized decision), with the demand price elasticity in traditional retail channel and the demand price elasticity in internet channel increase, product quality level, wholesale 
505 price, retail price, direct price, expected revenue and consumer surplus will all decrease.

506

Table2 The retailer dual channel structure (centralized decision)

\begin{tabular}{ccccccc}
\hline$\eta_{r}$ & $\eta_{e}$ & $q^{C^{*}}$ & $p_{r}^{C^{*}}$ & $p_{e}^{C^{*}}$ & $E \Pi_{M R}^{C^{*}}$ & $C S^{C^{*}}$ \\
\hline 1.000 & 2.000 & 4.033 & 38.383 & 23.258 & 145.519 & 31.090 \\
1.100 & 2.200 & 3.667 & 31.722 & 19.222 & 120.264 & 30.694 \\
1.200 & 2.400 & 3.361 & 26.655 & 16.152 & 101.055 & 29.993 \\
1.300 & 2.600 & 3.103 & 22.712 & 13.762 & 86.106 & 29.136 \\
1.400 & 2.800 & 2.881 & 19.583 & 11.866 & 74.244 & 28.209 \\
1.500 & 3.000 & 2.689 & 17.059 & 10.337 & 64.675 & 27.262 \\
1.600 & 3.200 & 2.521 & 14.993 & 9.085 & 56.843 & 26.324 \\
1.700 & 3.400 & 2.373 & 13.281 & 8.048 & 50.353 & 25.412 \\
1.800 & 3.600 & 2.241 & 11.847 & 7.178 & 44.913 & 24.534 \\
1.900 & 3.800 & 2.123 & 10.633 & 6.443 & 40.310 & 23.695 \\
2.000 & 4.000 & 2.017 & 9.596 & 5.815 & 36.380 & 22.898 \\
\hline
\end{tabular}

507 From Table 2, we can see that when the retailer establishes the dual channel structure 508 (centralized decision), compared with decentralized decision, product quality level, retail 509 price, joint expected revenue and consumer surplus will increase. But direct price will 510 decrease.

Table 3 The manufacturer dual channel structure

\begin{tabular}{ccccccccccc}
\hline$\eta_{r}$ & $\eta_{e}$ & $q^{T^{*}}$ & $w^{T^{*}}$ & $p_{r}^{T^{*}}$ & $p_{e}^{T^{*}}$ & $E \Pi_{R}^{T^{*}}$ & $E \Pi_{T}^{T^{*}}$ & $E \Pi_{M}^{T^{*}}$ & $E \Pi_{M R}^{T^{*}}$ & $C S^{T^{*}}$ \\
\hline 1.000 & 2.000 & 1.940 & 16.500 & 22.800 & 7.275 & 20.459 & 27.280 & 38.949 & 59.408 & 14.063 \\
1.100 & 2.200 & 1.764 & 13.636 & 18.843 & 6.012 & 16.908 & 22.545 & 32.189 & 49.098 & 14.027 \\
1.200 & 2.400 & 1.617 & 11.458 & 15.833 & 5.052 & 14.208 & 18.944 & 27.048 & 41.256 & 13.807 \\
1.300 & 2.600 & 1.492 & 9.763 & 13.491 & 4.305 & 12.106 & 16.142 & 23.047 & 35.153 & 13.487 \\
1.400 & 2.800 & 1.386 & 8.418 & 11.633 & 3.712 & 10.438 & 13.918 & 19.872 & 30.310 & 13.114 \\
1.500 & 3.000 & 1.293 & 7.333 & 10.133 & 3.233 & 9.093 & 12.124 & 17.311 & 26.404 & 12.717 \\
1.600 & 3.200 & 1.213 & 6.445 & 8.906 & 2.842 & 7.992 & 10.656 & 15.214 & 23.206 & 12.313 \\
1.700 & 3.400 & 1.141 & 5.709 & 7.889 & 2.517 & 7.079 & 9.439 & 13.477 & 20.556 & 11.914 \\
1.800 & 3.600 & 1.078 & 5.093 & 7.037 & 2.245 & 6.315 & 8.420 & 12.021 & 18.336 & 11.525 \\
\hline
\end{tabular}




\begin{tabular}{lllllllllll}
\hline 1.900 & 3.800 & 1.021 & 4.571 & 6.316 & 2.015 & 5.667 & 7.557 & 10.789 & 16.457 & 11.150 \\
2.000 & 4.000 & 0.970 & 4.125 & 5.700 & 1.819 & 5.115 & 6.820 & 9.737 & 14.852 & 10.791 \\
\hline
\end{tabular}

512

513

From Table 3, we can see that when the manufacturer establishes the dual channel structure (entrusting the third-party platform to build internet channel), compared with the retailer dual channel structure (decentralized decision and centralized decision), the product quality level, wholesale price, retail price, direct price, retailer's expected revenue, manufacturer's expected revenue, joint expected revenue, and consumer surplus will all decrease; with the demand price elasticity in internet channel increasing, the third-party platform's expected revenue will decrease.

(Figure 2 Comparison of product quality level under three situations)

We can find that the product quality level under centralized decision will be higher than that under decentralized decision, and will also be higher than when the manufacturer entrusts the third-party platform to build internet channel.

(Figure 3 The expected revenue functions under three situations)

We can find that the manufacturer's expected revenue and retailer's expected revenue under decentralized decision will be higher than that when the manufacturer entrusts the third-party platform. The joint expected revenue under centralized decision will be higher than that under decentralized decision, and also higher than that when the manufacturer entrusts the third-party platform.

(Figure 4 Consumer surplus under three situations)

From Figure 4, we can see that the customer's consumer surplus in the case pf centralized decision will be higher than that in the case of decentralized decision, and also higher than that when the manufacturer entrusts the third-party platform.

\section{Conclusions and Future Research}

Based on the three-stage Stackelberg dynamic game, this paper considers how to make product quality control strategy in the three-echelon supply chain composed of the manufacturer, retailer and customer when the retailer establishes the dual channel structure and the manufacturer establishes the dual channel structure. We analyze when there are decentralized decision and centralized decision, the demand price elasticity, market share 
ratio, revenue sharing ratio and quality cost coefficient how to influence the product demand, product quality level, retail price and direct price in different channels, expected revenue functions of the manufacturer and retailer, consumer surplus and product quality control strategy.

When the retailer establishes the dual channel structure (decentralized decision), with the demand price elasticity in traditional retail channel and the demand price elasticity in internet channel increase, product quality level, wholesale price, retail price, direct price, expected revenue and consumer surplus will all decrease. When the retailer establishes the dual channel structure (centralized decision), compared with decentralized decision, product quality level, retail price, joint expected revenue and consumer surplus will increase, but direct price will decrease. When the manufacturer establishes the dual channel structure (entrusting the third-party platform to build internet channel), compared with the retailer dual channel structure (decentralized decision and centralized decision), the product quality level, wholesale price, retail price, direct price, retailer's expected revenue, manufacturer's expected revenue, joint expected revenue, and consumer surplus will all decrease; with the demand price elasticity in internet channel increasing, the third-party platform's expected revenue will decrease.

The product quality level under centralized decision will be higher than that under decentralized decision, and higher than that when the manufacturer entrusts the third-party platform to build the internet channel; The manufacturer and retailer's expected revenues under decentralized decision will be higher than that when the manufacturer entrusts the third-party platform; The joint expected revenue under centralized decision will be higher than that under decentralized decision, and also higher than that when the manufacturer entrusts the third-party platform; The customer's consumer surplus under centralized decision will be higher than that under decentralized decision, and also higher than that when the manufacturer entrusts the third-party platform.

In our paper, the model only considers the situation of one manufacturer and one retailer or only entrusting one third-party platform, and it is a Stackelberg dynamic game under the condition of complete information. In future research, we will consider how to formulate product quality control strategy in different distribution channels under the 
condition of asymmetric information, and try to establish a multi-stage, dynamic and repeated game between the manufacturer and retailer or third-party platform to analyze the impact on product quality decision, expected revenue function, customer's consumer surplus and social welfare.

\section{Acknowledgments}

The authors are grateful to the referees for their valuable comments and their helps on how to improve the quality of our paper.

\section{Statistical data}

All the data is available and within the manuscript, no supplement materials data.

\section{Competing interests}

The authors declare that no competing interests exist.

\section{References}

Chen J.X., Liang L., Yao D.Q.,etc. Price and quality decisions in dual-channel supply chains. European Journal of Operational Research, 2017, 259(3): 935-948.

Chen X., Zhang H., Zhang M., etc. Optimal decisions in a retailer Stackelberg supply chain. International Journal of Production Economics, 2017, 187: 260-270.

Dey K., Roy S., Saha S. The impact of strategic inventory and procurement strategies on green product design in a two-period supply chain. International Journal of Production Research, 2019, 57(7): 1915-1948.

Feng L.P., Govindan K., Li C.F. Strategic planning: Design and coordination for dual-recycling channel reverse supply chain considering consumer behavior. European Journal of Operational Research, 2017, 260(2): 601-602.

Guo S.S., Heese H.S. Product variety and distribution channel structure. International Journal of Production Research, 2017, 55(12): 3392-3410.

Huang H.F., He Y., Chen J. Competitive strategies and quality to counter parallel importation in global market. Omega, 2019, 86: 173-197.

Jabarzare N., Rasti-Barzoki M. A game theoretic approach for pricing and determining quality level through coordination contracts in a dual-channel supply chain including manufacturer and packaging company. International Journal of Production Economics, 
2020, 221.

600

601

602

603

604

605

606

607

608

609

610

611

612

613

614

615

616

617

618

619

620

Lan Y.Q., Li Y.Z., Papier F. Competition and coordination in a three-tier supply chain with differentiated channels. European Journal of Operational Research, 2018, 269(3): 870-882.

Liu Y., Shi H.Y., Petruzzi N.C. Optimal quality and quantity provisions for centralized vs. decentralized distribution: Market size uncertainty effects. European Journal of Operational Research, 2018, 265(3): 1144-1158.

Luo Z., Chen X., Kai M. The effect of customer value and power structure on retail supply chain product choice and pricing decisions. Omega, 2018, 77: 115-126.

Matsui K. When should a manufacturer set its direct price and wholesale price in dual-channel supply chains?. European Journal of Operational Research, 2017, 258(2): 501-511.

Modak N.M., Kelle P. Managing a dual-channel supply chain under price and delivery-time dependent stochastic demand. European Journal of Operational Research, 2019, 272(1): 147-161.

Rahmani K, Yavari M. Pricing policies for a dual-channel green supply chain under demand disruptions. Computers \& Industrial Engineering, 2019, 127: 493-510.

Sarkar B., Saren S. Product inspection policy for an imperfect production system with inspection errors and warranty cost. European Journal of Operational Research, 2016, 248(1): 263-271.

Song B.Q., Li M.Z.F., Zhuang W.F. Dynamic channel control and pricing of a single perishable product on multiple distribution channels. European Journal of Operational Research, 2020, 288(2): 539-551.

Tian L., Jiang B.J. Effects of consumer-to-consumer product sharing on distribution channel. Production and Operations Management, 2018, 27(2): 350-367.

Wang C.X., Leng M.M., Liang L.P. Choosing an online retail channel for a manufacturer: Direct sales or consignment?. International Journal of Production Economics, 2018, 195(338): 358.

Wang L.S., Song H.M., Wang Y.Z. Pricing and service decisions of complementary products in a dual-channel supply chain. Computers \& Industrial Engineering, 2017, 
105: 223-233.

630 Wong H., Lesmono D., Chhajed D., et al. On the evaluation of commonality strategy in product line design: The effect of valuation change and distribution channel structure. Omega, 2019, 83: 14-25.

\section{Figure legends}

Figure 1. The relationship of dual channel structure

Figure 2. Comparison of product quality level under three situations

Figure 3. The expected revenue functions under three situations 
Figures

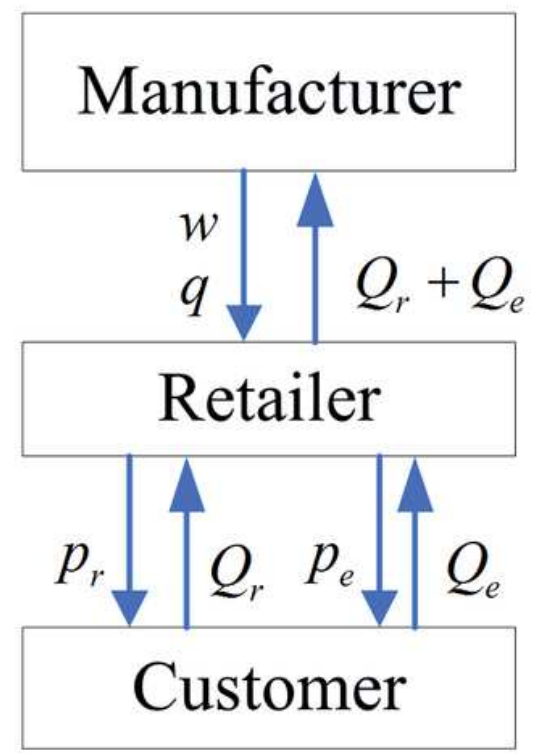

the retailer dual channel structure

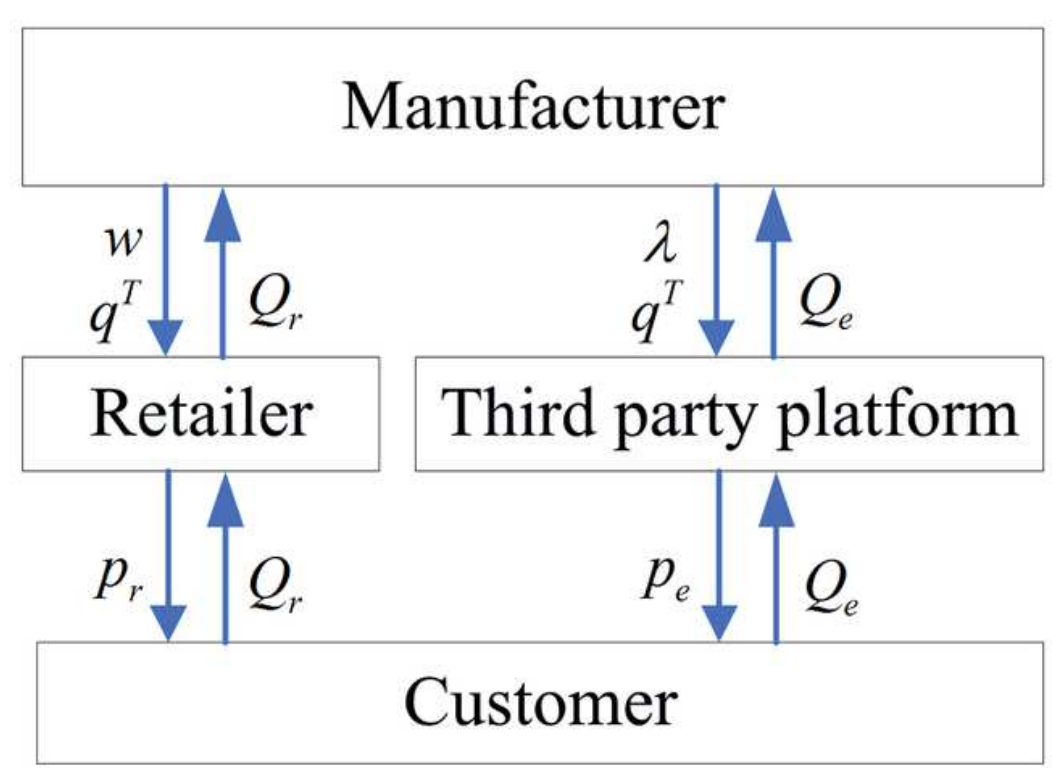

the manufacturer dual channel structure

\section{Figure 1}

The relationship of dual channel structure 


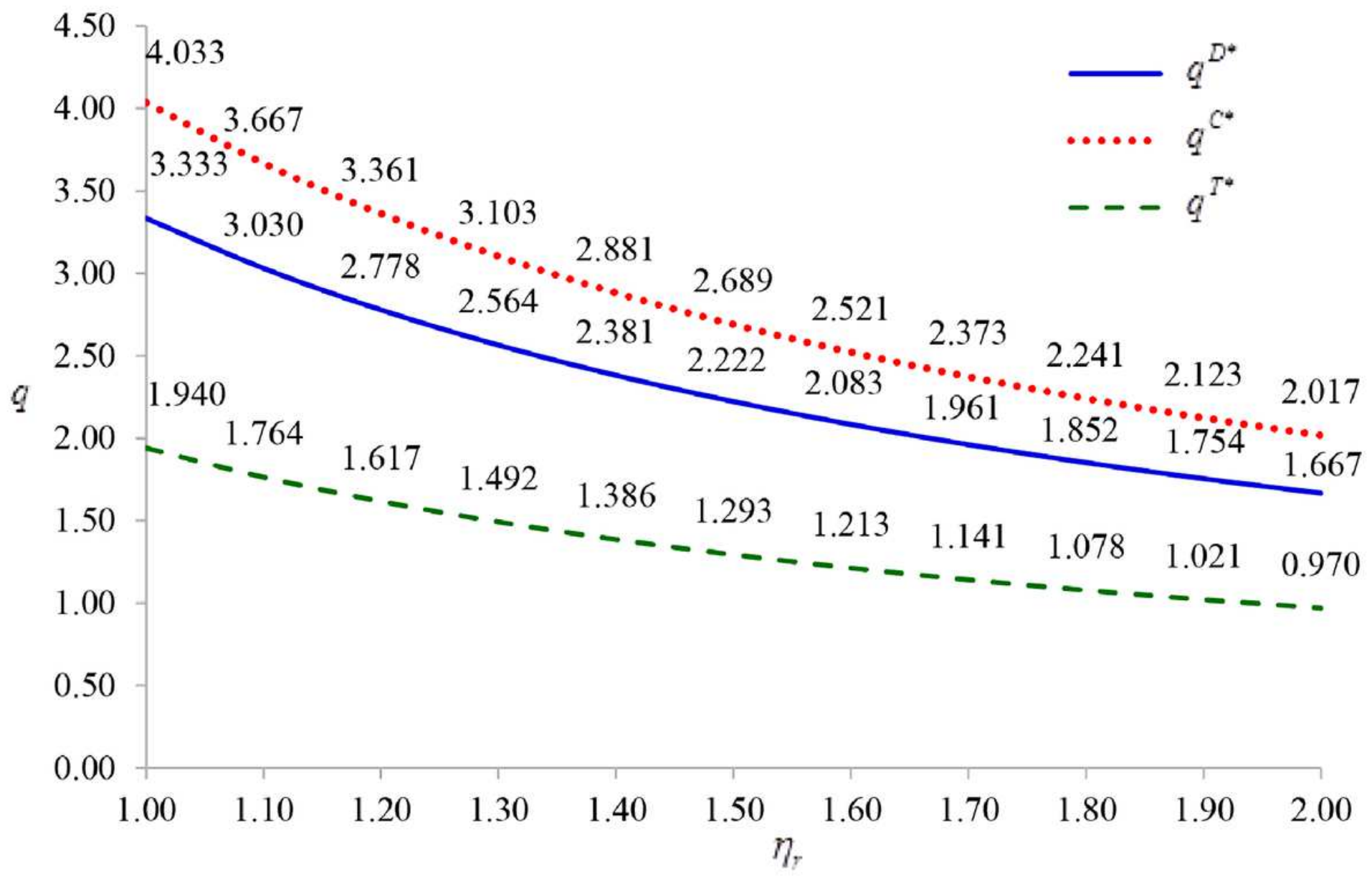

Figure 2

Comparison of product quality level under three situations 

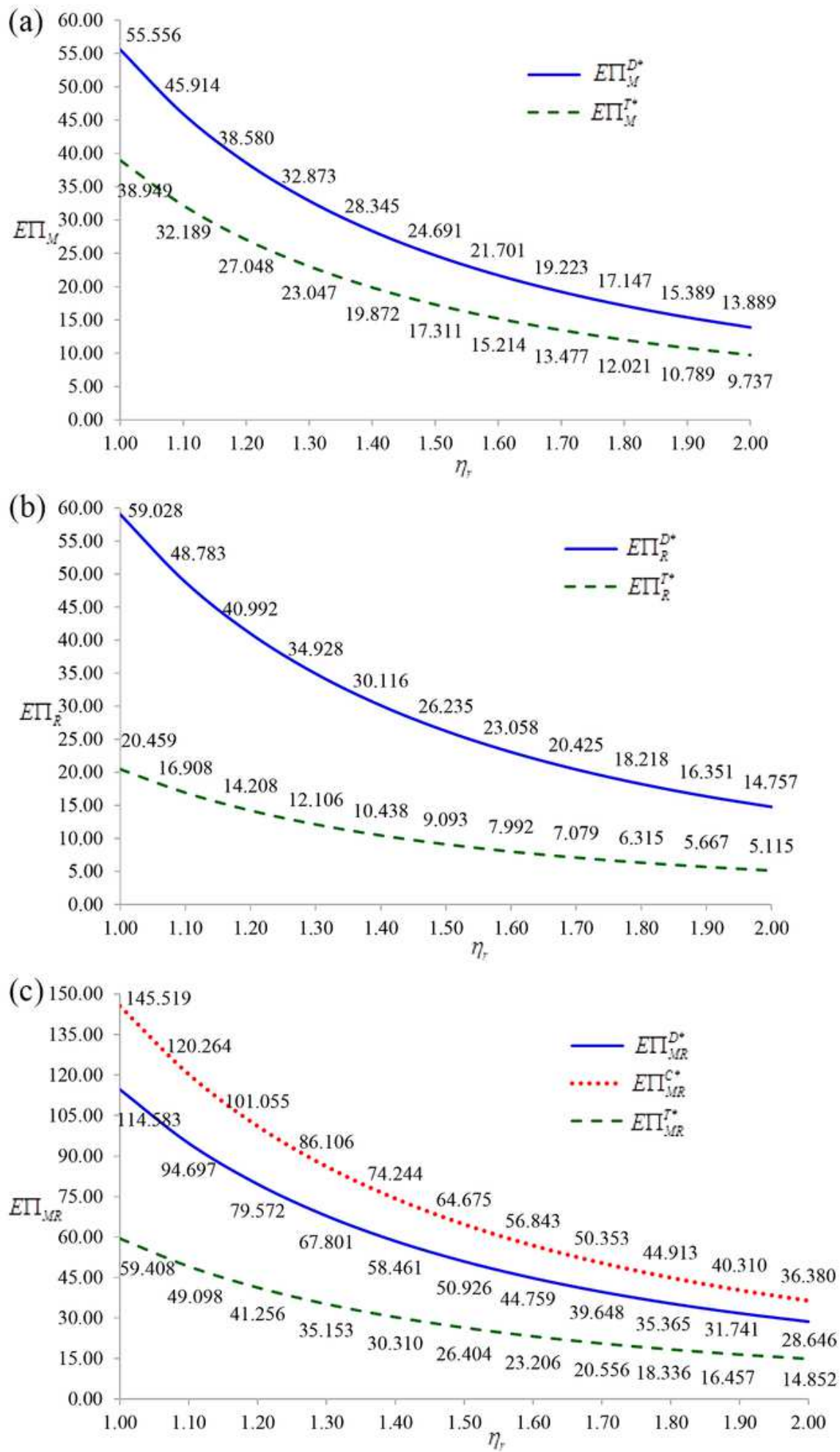

\section{Figure 3}

The expected revenue functions under three situations 


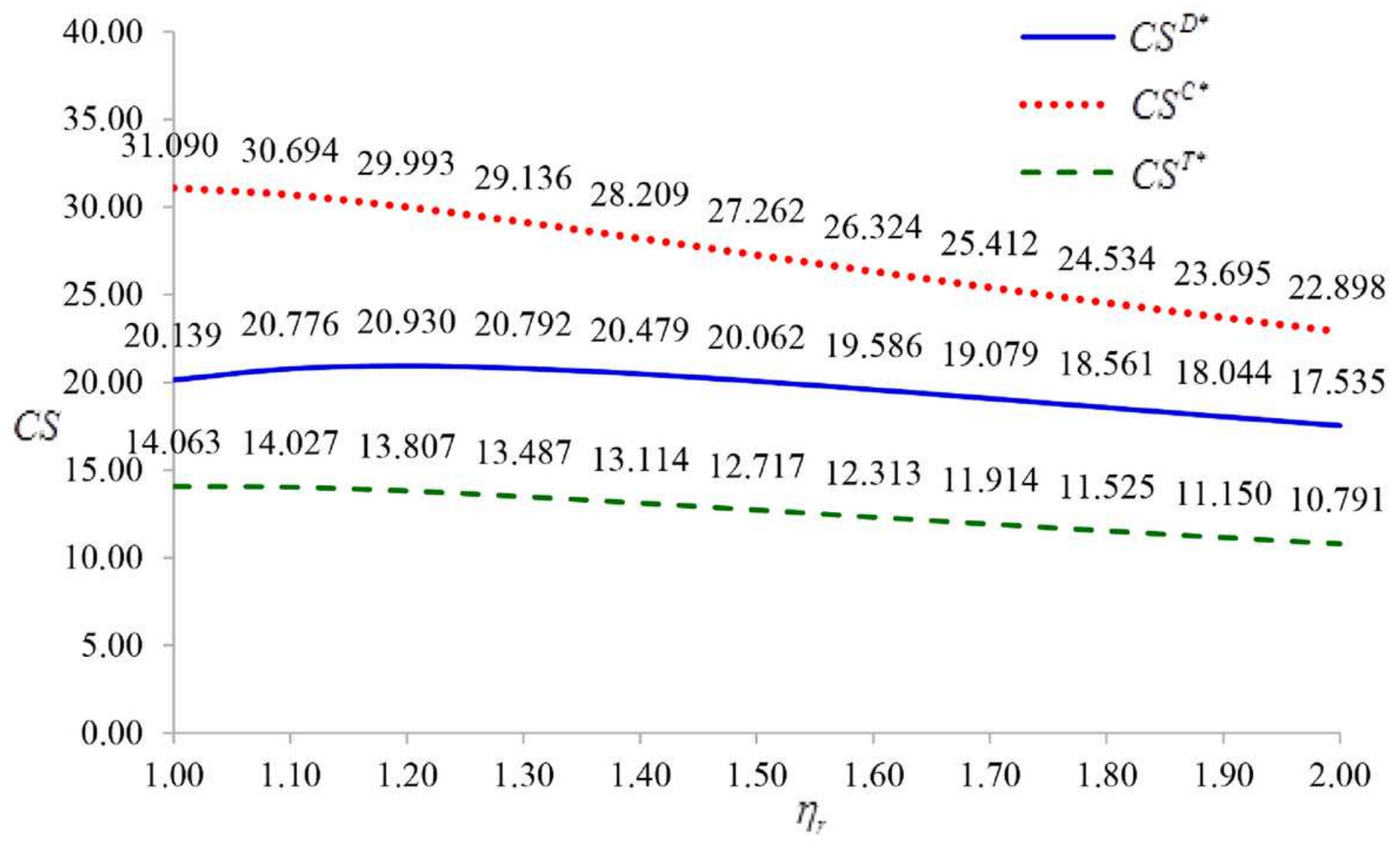

Figure 4

Consumer surplus under three situations 